Marquette University

e-Publications@Marquette

$1-1-2007$

\title{
Preparation of Chiral Cholestanofluorene and Its Electron-Rich Derivatives for Isolation of a Stable Cation-Radical Salt
}

Paromita Debroy

Marquette University

Ruchi Shukla

Marquette University

Sergey V. Lindeman

Marquette University, sergey.lindeman@marquette.edu

Rajendra Rathore

Marquette University

Accepted version. The Journal of Organic Chemistry, Vol. 72, No. 5 (2007): 1765-1769. DOI. (C) 2007 American Chemical Society. Used with permission. 
Marquette University

e-Publications@Marquette

\section{Chemistry Faculty Research and Publications/College of Arts and Sciences}

This paper is NOT THE PUBLISHED VERSION; but the author's final, peer-reviewed manuscript. The published version may be accessed by following the link in the citation below.

Journal of Organic Chemistry, Vol. 72, No. 5 (2007): 1765-1769. DOI. This article is (c) American Chemical Society and permission has been granted for this version to appear in $\mathrm{e}-$ Publications@Marquette. American Chemical Society does not grant permission for this article to be further copied/distributed or hosted elsewhere without the express permission from American Chemical Society.

\section{Preparation of Chiral Cholestanofluorene and Its Electron-Rich Derivatives for Isolation of a Stable Cation-Radical Salt}

\section{Paromita Debroy}

Department of Chemistry, Marquette University, Milwaukee, WI Ruchi Shukla

Department of Chemistry, Marquette University, Milwaukee, WI Sergey V. Lindeman

Department of Chemistry, Marquette University, Milwaukee, WI Rajendra Rathore

Department of Chemistry, Marquette University, Milwaukee, WI 


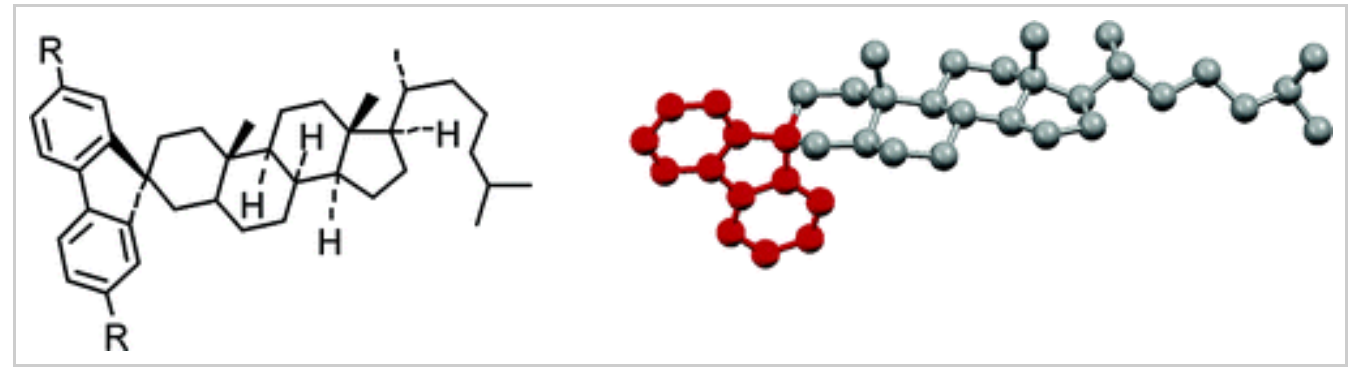

A simple and practical synthesis of a variety of chiral fluorene derivatives is described where a cholestane moiety is attached to the carbon 9 of the fluorene ring system from readily available starting materials. An appropriately substituted fluorene derivative (i.e., $\mathrm{R}=\mathrm{OMe}$ ) forms a highly colored (chiral) cation-radical that can be isolated as robust hexachloroantimonate salt. Interestingly, the simplest cholestanofluorene (i.e., $R=H$ ) can also be transformed into a dibromo derivative (i.e., $\mathrm{R}=\mathrm{Br}$ ), a precursor to the (poly)cholestanofluorenes where the cholestane moieties will serve not only as groups that impart chirality but also allow them to be soluble in common organic solvents. The details of these works are described.

\section{Introduction}

Poly(9,9-dialkylfluorenes), produced by polymerization of 9,9-dialkylfluorene, are extensively investigated as electroluminescent polymers for a variety of applications in the emerging area of molecular electronics and nanotechnology. 1,2 Much attention has been focused toward enhancing the processibility and the efficiency of polyfluorenes in functional devices by modifications of the groups attached at the 9 position of the fluorene moiety. ${ }^{1,2}$ Interestingly, an introduction of a readily available (chiral) cholestane unit onto the fluorene moiety (see structure A) can not only satisfy the processibility needs owing to the lipophilic nature of the (bio-compatible) cholestane moieties ${ }^{3}$ but can also impart chirality to the resulting fluorene derivatives. Moreover, the appropriately substituted cholestano-fluorene derivatives and its highly colored cation-radical salts may be potentially useful for the preparation of chiroptical switching devices ${ }^{4}$ as well as chiral liquid crystals. ${ }^{5}$ 


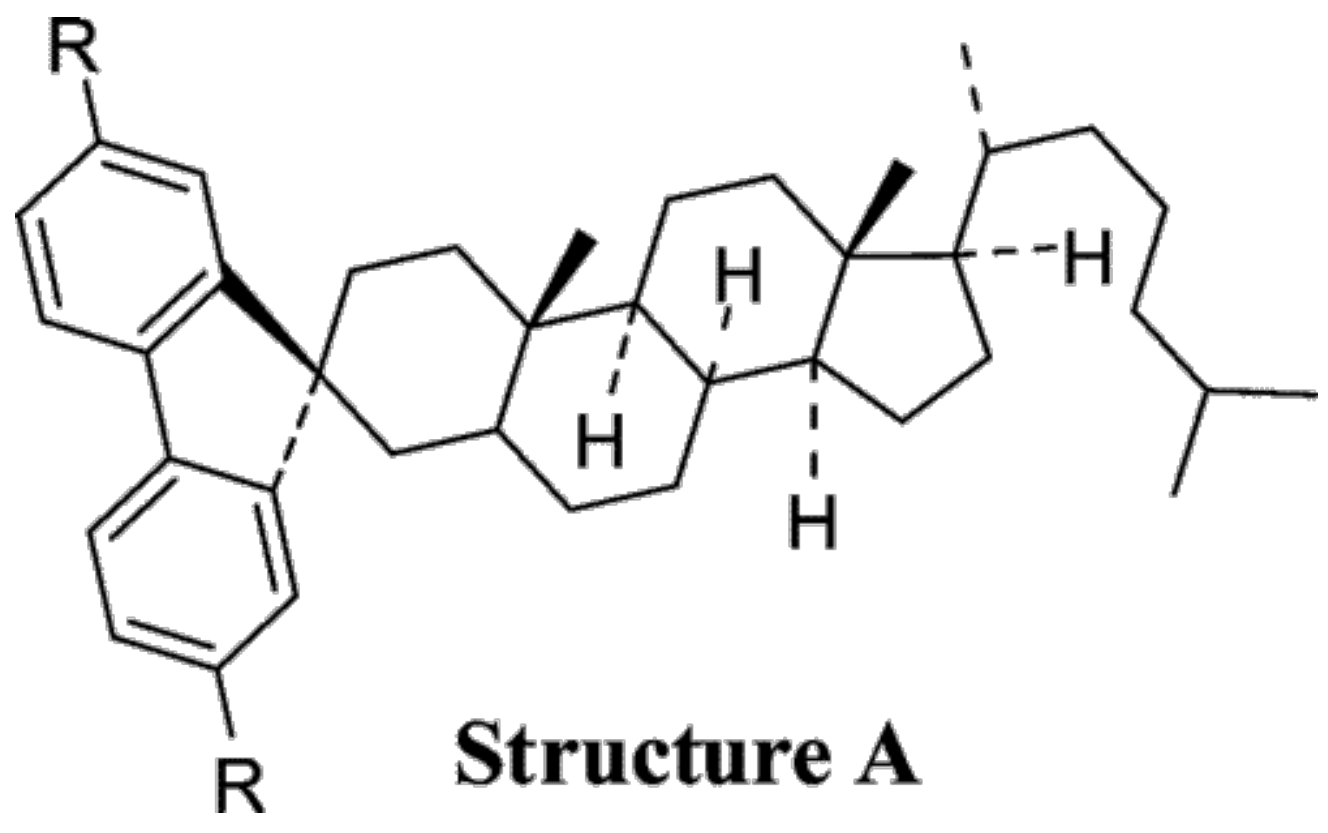

Accordingly, we now describe a simple and efficient synthesis of hitherto unknown cholestanofluorene (see structure $\mathbf{A}$ ) and its derivatives from the readily available cholestanone as the starting material. Also, the preparation of an electron-rich dimethoxycholestanofluorene derivative allows the isolation of a stable cation-radical salt by 1 electron oxidation, using a variety of oxidants as follows.

\section{Results and Discussion}

Our initial attempt to synthesize the parent cholestanofluorene (4) via a direct two-step route (Scheme 1) met with limited success. For example, a reaction of cholestanone (1) with either 2-biphenylmagnesium bromide or 2-biphenyllithium afforded at best a $\sim 20 \%$ yield of the tertiary alcohol 2. However, chromatographically purified tertiary alcohol 2 underwent a smooth intramolecular Friedel-Crafts alkylation in dichloromethane in the presence of a catalytic amount of methanesulfonic acid via cationic intermediate $\mathbf{3}$ to produce cholestanofluorene $\mathbf{4}$ in quantitative yield. The repeated (failed) attempts to improve the yield of alcohol $\mathbf{2}$-a precursor for the cationic intermediate $\mathbf{3}$ - suggested that an alternative (general) approach was desired for the preparation of $\mathbf{4}$ and its derivatives. It was envisioned that the same cationic intermediate $\mathbf{3}$ could also be produced by protonation of an alkene derivative $\mathbf{5}$, which may, in turn, be obtained by an efficient palladium-catalyzed coupling ${ }^{6}$ of the 2-biphenylmagnesium bromide with hitherto unknown 3-bromocholestene 6, i.e., Scheme 1. 

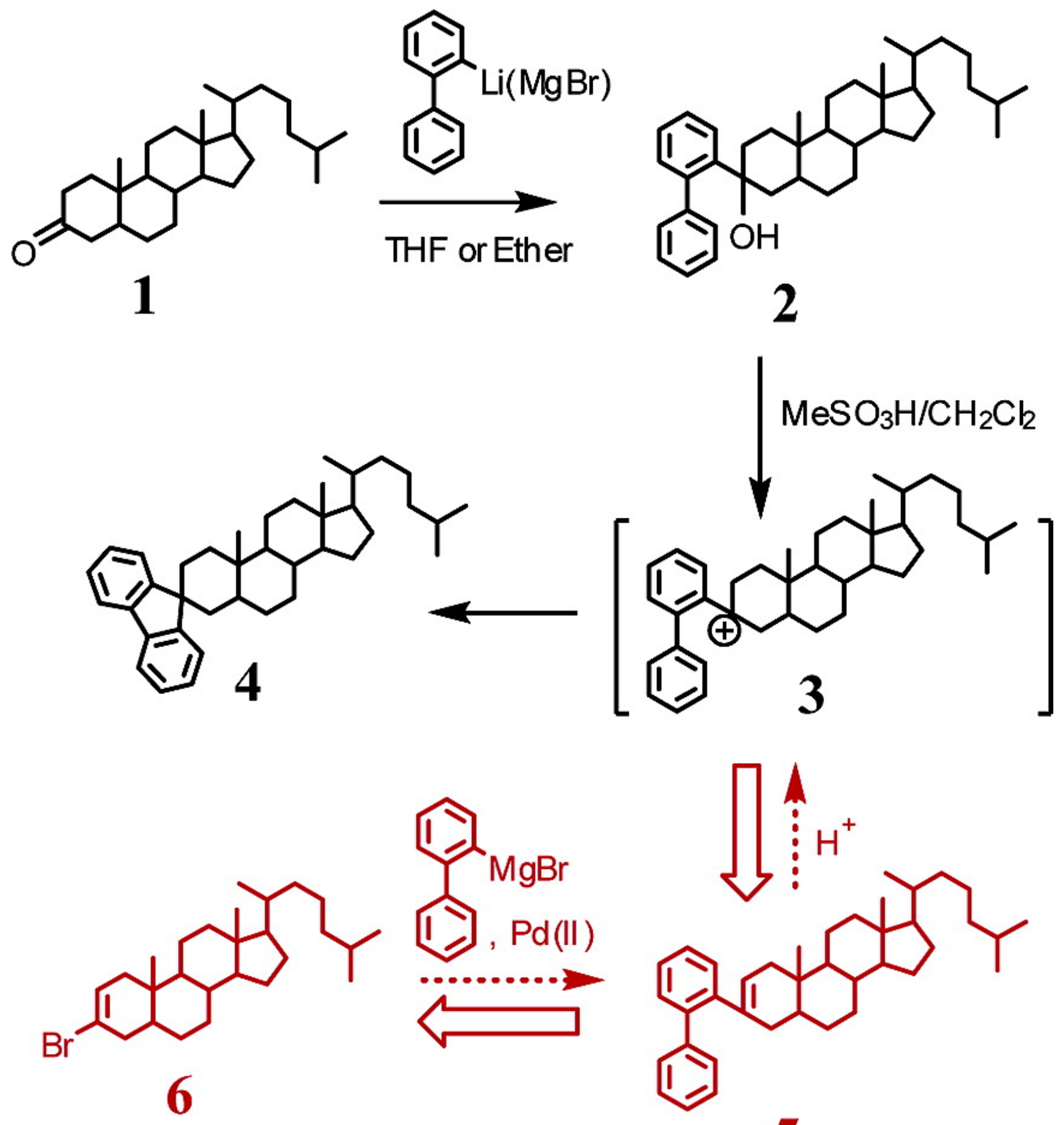

Scheme 1

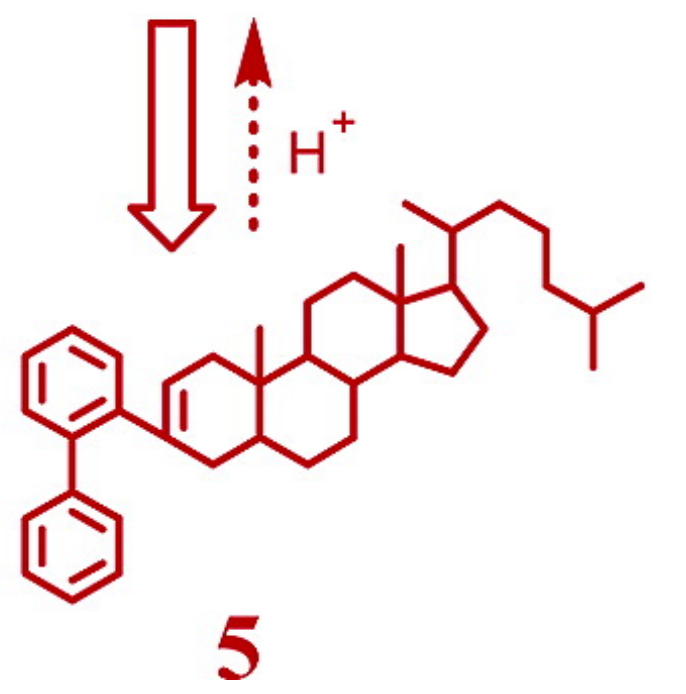

Fortunately, employing a simple 3-step sequence ${ }^{7}$ afforded an isomeric mixture of 3bromocholest-2(3)-enes 6 from commercially available cholestanone in excellent yield without a need for chromatographic purification, i.e., Scheme 2. 


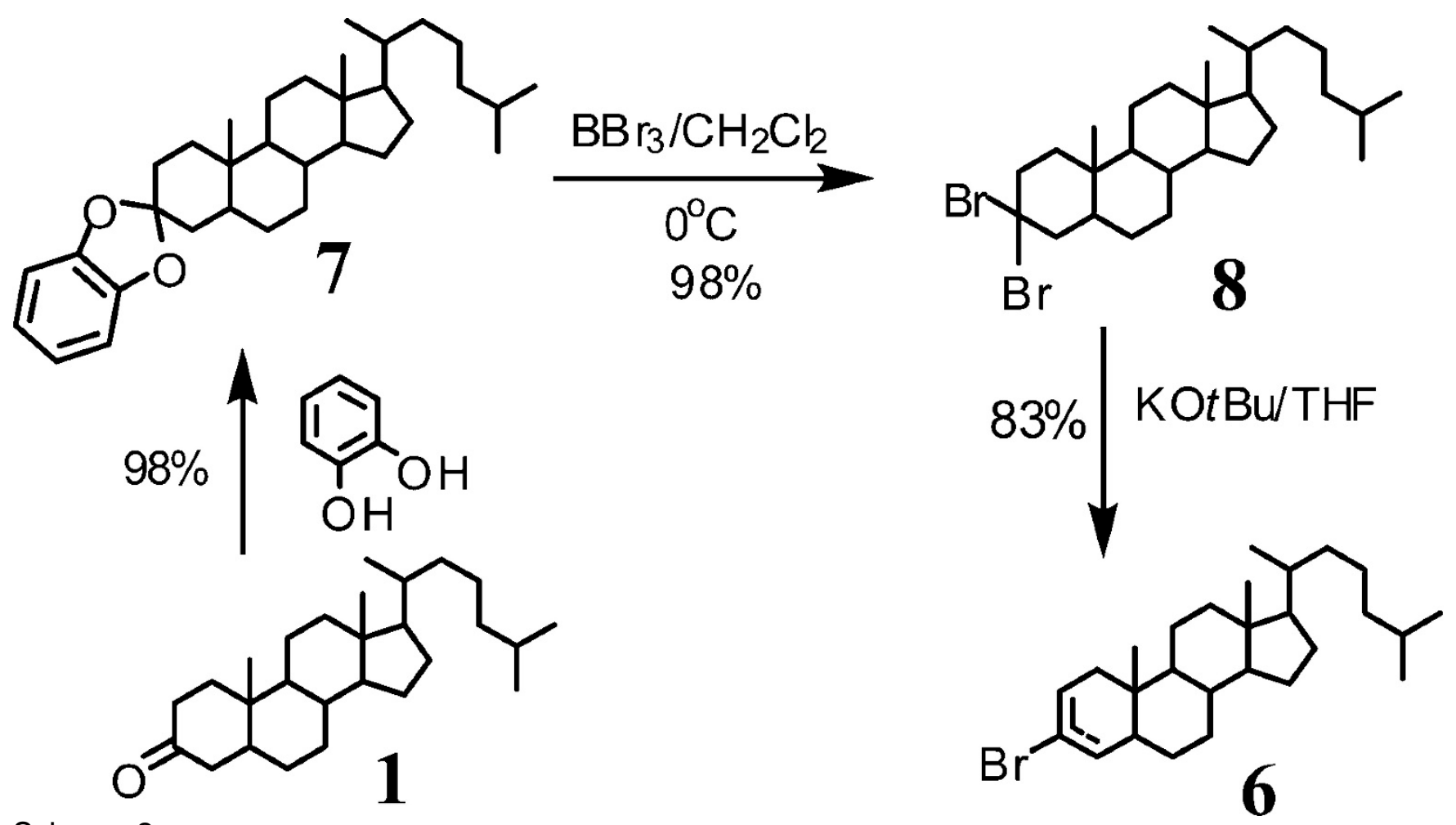

Scheme 2

Thus, a reaction of cholestanone (1) with catechol in benzene in the presence of an acid catalyst ${ }^{8}$ afforded 1,3 benzodioxole derivative (7) quantitatively. A reaction of 7 with boron tribromide in dichloromethane at $0{ }^{\circ} \mathrm{C}$ afforded exclusively a gem-dibromo derivative 8 in $98 \%$ yield. ${ }^{7} \mathrm{~A}$ dehydrobromination of the crude 8 in tetrahydrofuran in the presence of potassium tert-butoxide afforded roughly an 8:2 isomeric mixture of 3-bromocholest-2(3)enes 6 in 83\% yield. It is noteworthy that all three steps can be easily carried out without a need for chromatographic purification of the intermediates or the final product. Note that the molecular structures of the intermediates $\mathbf{7}$ and $\mathbf{8}$ were also confirmed by X-ray crystallography (see the Experimental Section and the Supporting Information for details).

Expectedly, a simple palladium-catalyzed coupling ${ }^{6}$ between the isomeric mixture of bromocholestenes $\mathbf{6}$ and the biphenylmagnesium bromide in the presence of a catalytic amount of bis(triphenylphosphine)palladium dichloride in refluxing tetrahydrofuran afforded a mixture of 3-biphenylcholestenes 5 in good yield. The ${ }^{1} \mathrm{H}$ NMR spectrum of the crude material clearly showed that signals due to the olefinic hydrogens of $\mathbf{6}$ as symmetrical multiples at 5.66 and $5.91 \mathrm{ppm}$ were shifted to 5.30 and $5.53 \mathrm{ppm}$, respectively. The isomeric mixture of 3biphenylcholestenes $\mathbf{5}$ were subjected to Friedel-Crafts cyclization in dichloromethane containing methanesulfonic acid at $0{ }^{\circ} \mathrm{C}$ to afford single cholestanofluorene 4 in good overall yield in two steps, i.e., eq 1. 


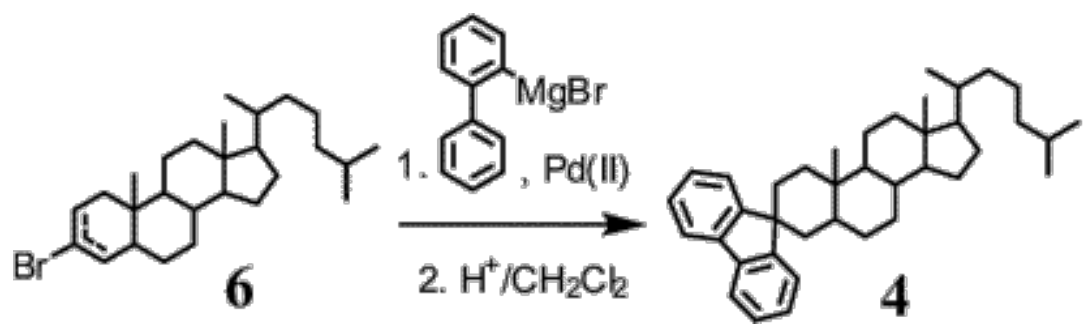

The molecular structure of 4 was established by ${ }^{1} \mathrm{H} /{ }^{13} \mathrm{C}$ NMR spectroscopy, ${ }^{9 \mathrm{a}}$ mass spectrometry, and elemental analysis, and was further confirmed by X-ray crystallography (Figure 1). The molecular geometries of the fluorene as well as of the cholestane moieties in 4 are comparable to those found in 9,9-dimethylfluorene and in various cholestane derivatives, respectively. ${ }^{9 b}$ Notably, however, a head-to-tail packing arrangement of 4 in the crystalline state where the H's on the perfectly ordered $\mathrm{C} 17$-aliphatic chains of cholestane frameworks make short $\mathrm{C}-\mathrm{H} \cdots \pi$ contacts (with distances of 2.7-3.0 $\AA$ ) with both faces of the fluorene rings is uniquely different from other 9,9-dialkylfluorenes (see Figure 1). Such a packing arrangement may prove to be highly beneficial for the device constructions with use of poly(cholestanofluorenes) as opposed to the traditional poly(9,9-dialkylfluorenes) with simple alkyl chains (vide infra).

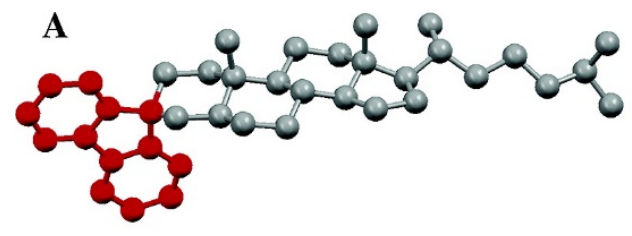

B

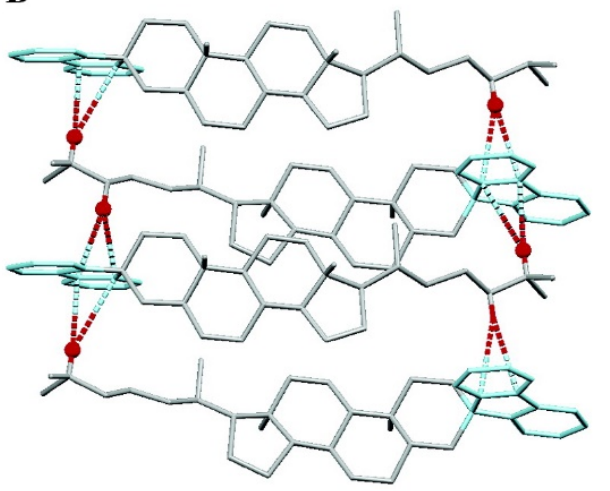

C

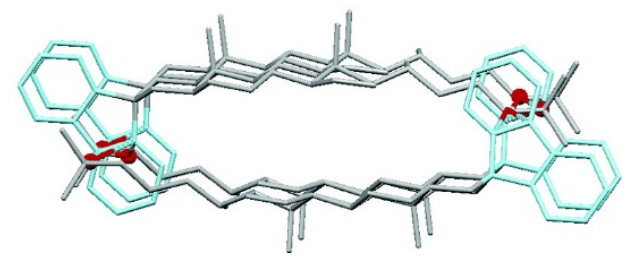

Figure 1 The molecular structure of cholestanofluorene $4(A)$ and the packing diagrams (B and C) showing the sandwiching of the C17-aliphatic chains of cholestane frameworks due to $\mathrm{C}-\mathrm{H} \cdots \pi$ interactions. 
The versatility of the synthetic strategy in eq 1 allows the preparation of electron-rich 2,7dimethoxyfluorene derivative for the isolation of (stable) chiral cation-radical salt with ease. For example, a cholestanofluorene derivative with methoxy substituents (i.e., 9) was easily obtained by a reaction of 4,4'-dimethoxybiphenyl-2-magnesium bromide ${ }^{10}$ with bromocholestenes (6) in the presence of a catalytic amount of bis-triphenylphosphinepalladium dichloride in tetrahydrofuran followed by cyclization with methanesulfonic acid at $0{ }^{\circ} \mathrm{C}$ in $77 \%$ isolated yield, i.e., eq 2.

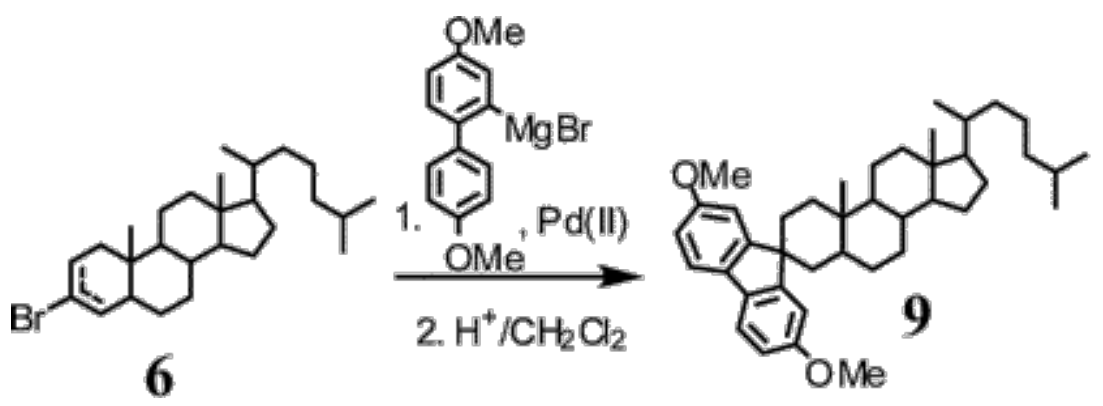

With the dimethoxycholestanofluorene 9 at hand, we first evaluated its electron-donor strength and the initial indication of the cation radical stability by cyclic voltammetry. Thus, donor 9 was subjected to electrochemical oxidation at a platinum electrode as a $2.5 \times 10^{-3} \mathrm{M}$ solution in dichloromethane containing $0.1 \mathrm{M} \mathrm{n}-\mathrm{Bu}_{4} \mathrm{NPF}_{6}$ as the supporting electrolyte. The cyclic voltammograms of $\mathbf{9}$ consistently met the reversibility criteria at various scan rates of $25-400$ $\mathrm{mV} \mathrm{s}^{-1}$ (see Figure 2), as they all showed cathodic/anodic peak current ratios of $i_{\mathrm{a}} / i_{\mathrm{c}}=1.0$ (theoretical) as well as the differences between anodic and cathodic peak potentials of $p_{\mathrm{a}}-p_{\mathrm{c}} \approx 70 \mathrm{mV}$ at $22^{\circ} \mathrm{C}$. A quantitative evaluation of the $\mathrm{CV}$ peak current with added ferrocene (as an internal standard) revealed that the oxidation potential of 9 ( $E_{\mathrm{ox}}=1.08 \mathrm{~V}$ vs SCE) was significantly lower than the (irreversible) redox potential $\left(E_{\mathrm{ox}}=1.71 \mathrm{~V}\right)$ for the parent cholestanofluorene 4 . 


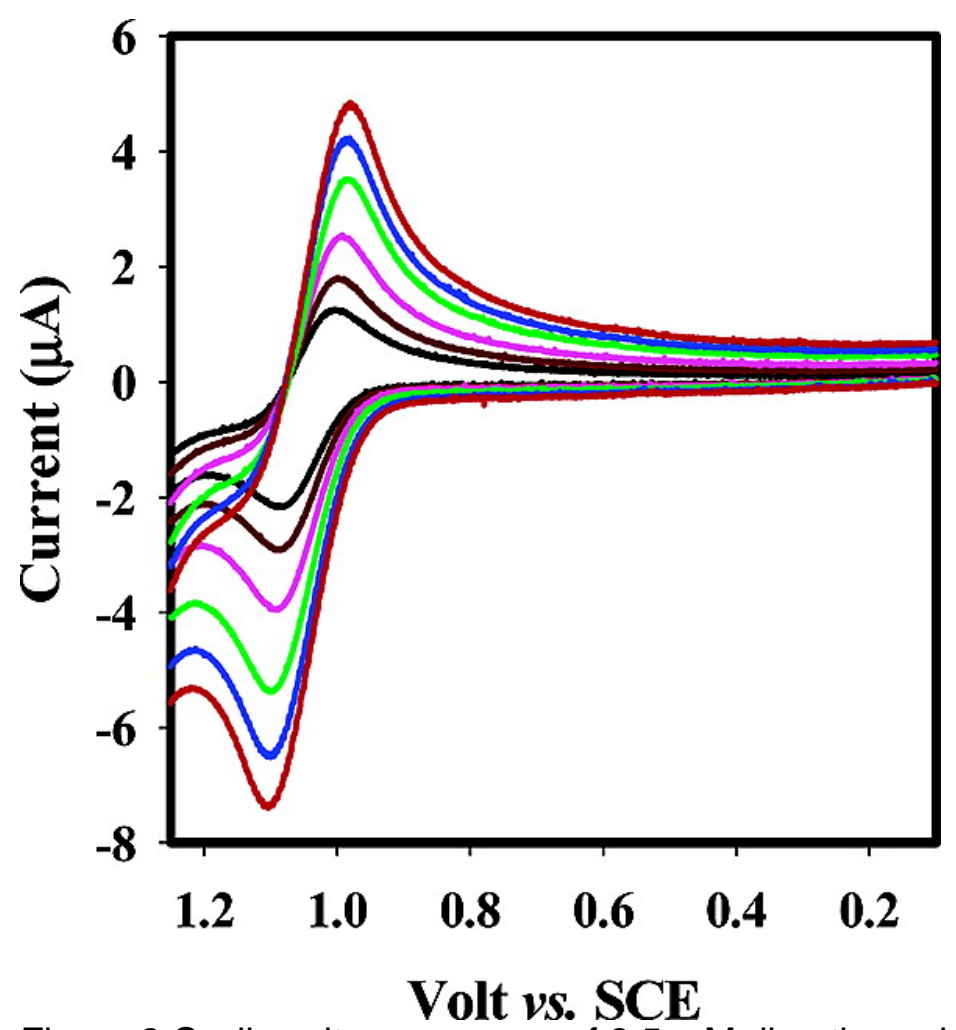

Figure 2 Cyclic voltammograms of $2.5 \mathrm{mM}$ dimethoxycholestano-fluorene 9 in $\mathrm{CH}_{2} \mathrm{Cl}_{2}$ containing $0.1 \mathrm{M}$ tetra- $n$-butylammonium hexafluorophosphate at a scan rate of $25-400 \mathrm{mV} \mathrm{s}^{-1}$ at $22{ }^{\circ} \mathrm{C}$.

The electrochemical reversibility of $\mathbf{9}$ and its relatively low oxidation potential prompted us to carry out its oxidation to the corresponding cation radical using a stable cation-radical salt $\mathrm{MA}^{+\cdot} \mathrm{SbCl}{ }^{-}$as an aromatic oxidant ( $E_{\text {red }}=1.11 \mathrm{~V}$ vs SCE). ${ }^{11}$ Thus, Figure 3 shows the spectral changes attendant upon the reduction of $3.1 \times 10^{-5} \mathrm{M} \mathrm{MA}^{+\cdot}\left[\lambda_{\max }(\log \varepsilon)=518 \mathrm{~nm}\right.$ (3.86)] by incremental additions of $1.9 \times 10^{-3} \mathrm{M}$ at $22^{\circ} \mathrm{C}$ in dichloromethane. The presence of well-defined isosbestic points at $\lambda_{\max }=443$ and $544 \mathrm{~nm}$ in Figure 3 are indicative of the uncluttered character of the electron transfer. Furthermore, a plot of the depletion of $\mathbf{M A}^{+\bullet}$ (i.e., decrease in the absorbance at $518 \mathrm{~nm}$ ) and formation of $\mathbf{9}^{+\cdot}$ (i.e., increase in the absorbance at $780 \mathrm{~nm}$ ) against the increments of added 9 (inset, Figure 3) established that $\mathbf{M A}^{+\bullet}$ was completely consumed after the addition of 1 equiv of 9 ; and the resulting absorption spectrum of the green $\mathbf{9}^{+\bullet}\left[\lambda_{\max }=420,700\right.$, and $\left.768 \mathrm{~nm}\right]$ remained unchanged upon further addition of neutral 9, i.e., eq 3. 


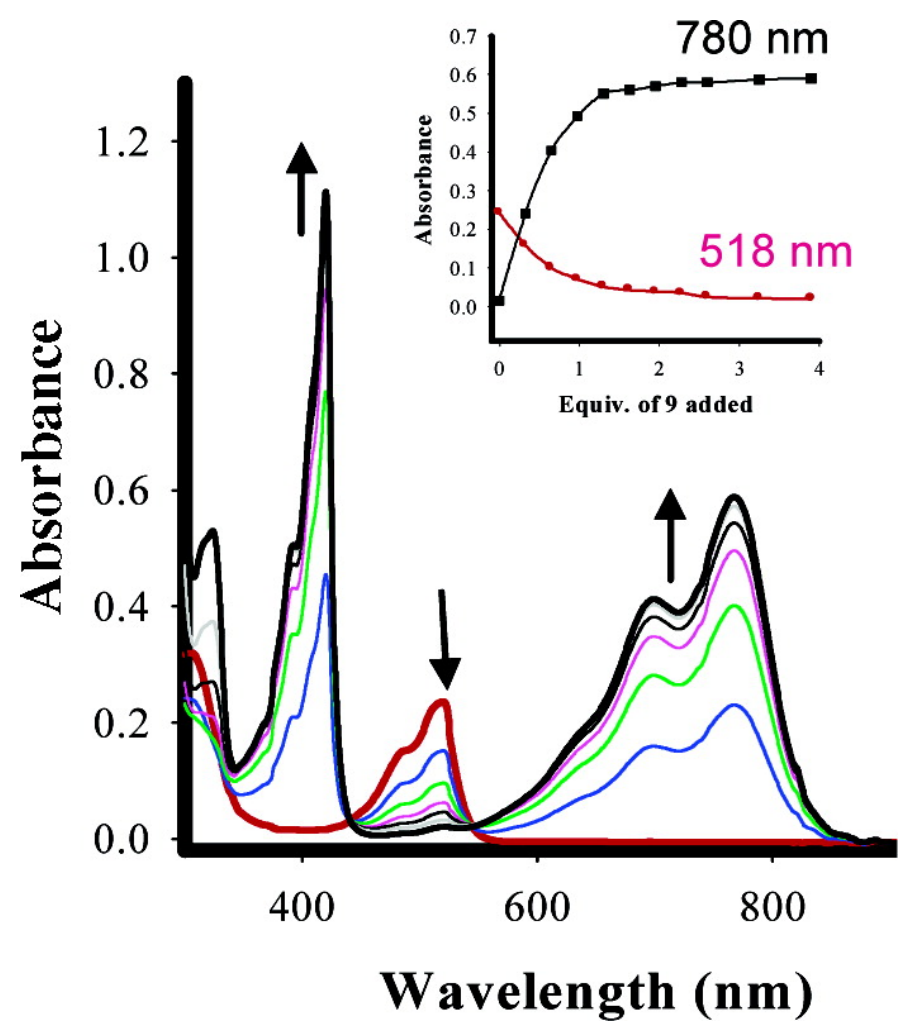

Figure 3 Spectral changes upon the reduction of $3.1 \times 10^{-5} \mathrm{M} \mathrm{MA}^{+\cdot}($ red) by incremental addition of 1.9 $\times 10^{-3} \mathrm{M} 9$ to $9^{+\bullet}$ in dichloromethane at $22^{\circ} \mathrm{C}$. Inset: A plot of depletion of absorbance of $\mathbf{M A}^{+\bullet}$ (circles, monitored at $518 \mathrm{~nm}$ ) and an increase of the absorbance of $\mathbf{9}^{+\bullet}$ (squares, monitored at $780 \mathrm{~nm}$ ) against the equivalent of added 9.

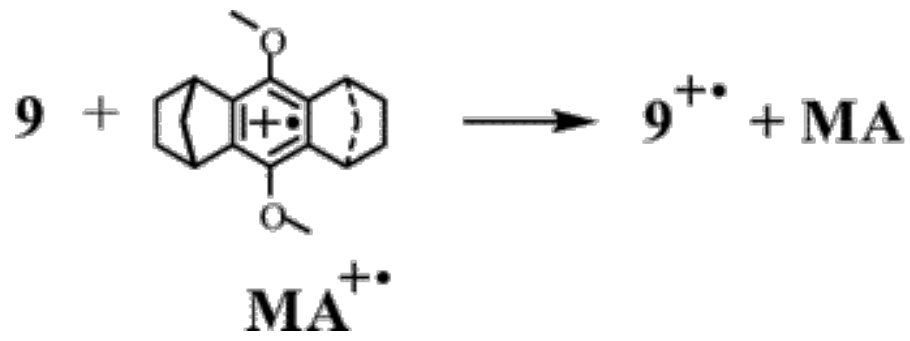

It is noteworthy that the green $\mathbf{9}^{+\bullet}$ obtained in eq 3 is highly persistent at room temperature and did not show any decomposition during a $12 \mathrm{~h}$ period at $22^{\circ} \mathrm{C}$. The high stability of the $9^{+\bullet}$ allowed the isolation of its crystalline salt as follows. Thus, a treatment of a solution of 9 with nitrosonium hexachloroantimonate $\left(\mathrm{NOSbCl}_{6}\right)$ in anhydrous dichloromethane at $0{ }^{\circ} \mathrm{C}$ immediately resulted in a dark green solution (vide infra) from which the microcrystalline salt $\left[9^{+\cdot} \mathrm{SbCl}_{6}^{-}\right]$was isolated, by precipitation with hexanes, in nearly quantitative yield according to the stoichiometry in eq $4 .^{12}$

$$
\mathbf{9}+\mathrm{NO} \mathrm{SbCl}_{6} \rightarrow 9^{+*} \mathrm{SbCl}_{6}+\mathrm{NO} \uparrow
$$

The highly colored $\mathbf{9}^{+\cdot} \mathrm{SbCl}_{6}^{-}$salt obtained in eq 4 was found to be extremely robust and can be recrystallized from a dichloromethane solution by a slow diffusion of toluene at $-20{ }^{\circ} \mathrm{C}$. 
Unfortunately, however, repeated attempts to obtain single crystals suitable for X-ray crystallography of $\left[9^{+\cdot} \mathrm{SbCl}_{6}^{-}\right]$were thus far unsuccessful.

In summary, we have presented a facile approach for the synthesis of chiral cholestanofluorenes from readily available starting materials and have shown that its methoxy derivative 9 forms a stable cation-radical salt - a potentially important material for the applications in the area of chiroptical switching devices. ${ }^{4}$ Moreover, parent cholestanofluorene 4 can be easily derivatized by electrophilic substitution reactions at 2,7positions, i.e., a reaction of 4 with tert-butyl chloride in dichloromethane containing a catalytic amount of ferric chloride afforded 2,7-di-tert-butyl derivative 10 in 92\% yield ${ }^{13}$ (Scheme 3), whereas a bromination reaction produces the corresponding dibromo derivative $\mathbf{1 1}$ in $97 \%$ yield, i.e., Scheme 3.

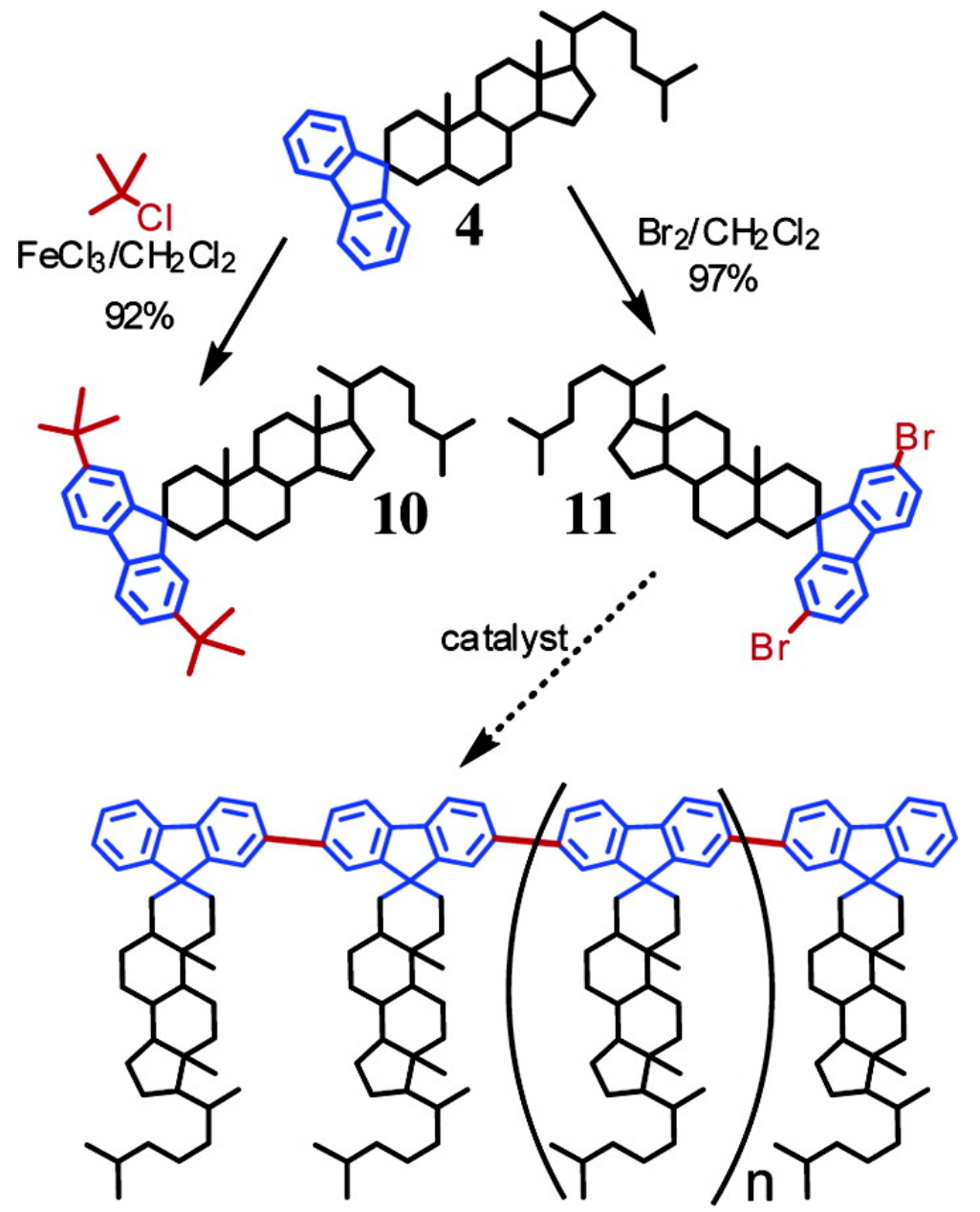

Scheme 3

The availability of dibromo derivative $\mathbf{1 1}$ will allow its ready transformation to the chiral poly(cholestanofluorenes) with standard palladium or nickel catalysts. ${ }^{14}$ The poly(cholestanofluorenes) can also be accessed via anodic oxidation of parent $4 .{ }^{15}$ These works are being pursued actively. 


\section{Experimental Section}

Cholestanone was prepared according to a literature procedure. ${ }^{16}$ Nitrosonium

hexachloroantimonate was prepared from a reaction of $\mathrm{SbCl}_{5}$ and $\mathrm{NOCl}$ in dichloromethane at $-78^{\circ} \mathrm{C}$ and the resulting salt was recrystallized from a dichloromethane-hexanes mixture and stored in an inert-atmosphere glovebox. ${ }^{13}$ (See the Supporting Information for a General Experimental Section.)

Spiro[1,3-benzodioxole-2,3'-cholestane] (7). The ketal 7 was synthesized by a reaction of cholestanone $(9.4 \mathrm{~g}, 24.4 \mathrm{mmol})$ with catechol $(7.8 \mathrm{~g}, 70.8 \mathrm{mmol})$ according to a slightly modified literature procedure. ${ }^{8}$ Thus, after completion of the reaction, the catalyst was removed by filtration through a pad of celite and the pad was washed further with ether $(3 \times 50$ $\mathrm{mL}$ ). The solvent was removed in vacuo and the resulting residue was dissolved in dichloromethane $(200 \mathrm{~mL}$ ) and washed successively with $10 \%$ potassium hydroxide, water, and brine, then dried over anhydrous magnesium sulfate. Evaporation of the solvent afforded 7 as a white solid in nearly quantitative yield $\left(11.4 \mathrm{~g}, 98 \%\right.$ ): $\mathrm{mp} 155-156{ }^{\circ} \mathrm{C}$ (lit. ${ }^{8} \mathrm{mp}$ 155-156 $\left.{ }^{\circ} \mathrm{C}\right) ;{ }^{1} \mathrm{H}$ NMR $\left(\mathrm{CDCl}_{3}\right) \delta 0.67-2.07$ (m, 46H, cholestane framework protons), 6.70-6.79 (m, 4H); ${ }^{13} \mathrm{C} \mathrm{NMR}\left(\mathrm{CDCl}_{3}\right) \delta 11.7,12.3,18.9,21.5,22.8,23.1,24.1,24.5,28.2$, 28.5, 28.6, 31.5, 32.0, 35.4, 35.7, 36.1, 36.4, 38.1, 39.7, 40.2, 42.8, 42.9, 53.9, 56.4, 56.6, 108.4, 108.6, 118.5, 121.0, 147.3, 147.5; GC-MS m/z $478\left(\mathrm{M}^{+}\right), 478$ calcd for $\mathrm{C}_{33} \mathrm{H}_{50} \mathrm{O}_{2}$. Note that the white solid, obtained above, was sufficiently pure and used in the next step without further purification. Moreover, an excellent quality of single crystals were obtained by a simple crystallization from a mixture of dichloromethane-acetonitrile and were further characterized by X-ray crystallography (see the Supporting Information).

3,3-Dibromocholestane (8). ${ }^{7}$ To a stirred solution of $7(8.9 \mathrm{~g}, 18.6 \mathrm{mmol})$ in dichloromethane $\left(40 \mathrm{~mL}\right.$ ) at $0{ }^{\circ} \mathrm{C}$ was added dropwise a $1 \mathrm{M}$ solution of boron tribromide in dichloromethane (23 $\mathrm{mL}, 23 \mathrm{mmol}$ ) under an argon atmosphere and the resulting mixture was stirred for $12 \mathrm{~h}$ while maintaining the temperature at $0{ }^{\circ} \mathrm{C}$. The reaction was quenched with ice-cold water $(50 \mathrm{~mL})$ and the dichloromethane layer was separated. The aqueous layer was extracted with dichloromethane $(3 \times 25 \mathrm{~mL})$. The combined organic extracts were washed successively with water $(50 \mathrm{~mL}), 10 \%$ sodium hydroxide $(2 \times 25 \mathrm{~mL})$, and water $(50 \mathrm{~mL})$, then dried over anhydrous magnesium sulfate. Recrystallization of the resulting crude solid from a mixture of dichloromethane/acetonitrile afforded 8 as a white solid in nearly quantitative yield $(9.7 \mathrm{~g}$, 98\%): $\mathrm{mp} 150-151^{\circ} \mathrm{C}\left(\mathrm{CH}_{2} \mathrm{Cl}_{2} / \mathrm{CH}_{3} \mathrm{CN}\right) ;{ }^{1} \mathrm{H}$ NMR $\left(\mathrm{CDCl}_{3}\right) \delta$ 0.61-2.60 (m, 46H, cholestane framework protons); ${ }^{13} \mathrm{C}$ NMR $\left(\mathrm{CDCl}_{3}\right) \delta 12.2,12.7,18.8,21.2,22.7,23.0,24.0,24.3,27.4$, 28.2, 28.4, 31.8, 35.5, 35.7, 36.0, 36.3, 37.4, 39.7, 40.4, 42.8, 44.9, 46.2, 52.0, 53.8, 56.4, 
56.5, 72.1. Anal. Calcd for $\mathrm{C}_{27} \mathrm{H}_{46} \mathrm{Br}_{2}$ : $\mathrm{C}, 61.13 ; \mathrm{H}, 8.74$. Found: $\mathrm{C}, 61.24 ; \mathrm{H}, 8.65$. HRMS

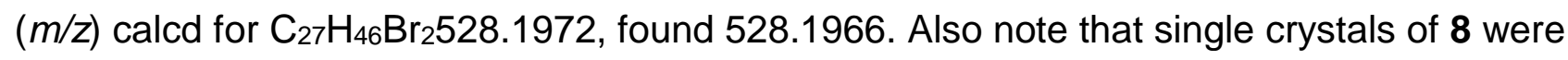
obtained by crystallization from a mixture of dichloromethane-acetonitrile and were characterized by X-ray crystallography (see the Supporting Information).

3-Bromocholestenes (6). To a magnetically stirred solution of 8 (8.8 g, $16.7 \mathrm{mmol})$ in anhydrous tetrahydrofuran $(50 \mathrm{~mL})$ was added excess potassium tert-butoxide $(3.4 \mathrm{~g}, 30$ $\mathrm{mmol})$. The resulting mixture was stirred under an argon atmosphere for $3 \mathrm{~h}$ at room temperature. The reaction was quenched with saturated ammonium chloride solution $(50 \mathrm{~mL})$ and triturated with dichloromethane $(100 \mathrm{~mL})$. The organic layer was separated and the aqueous layer was further extracted with dichloromethane $(3 \times 25 \mathrm{~mL})$. Combined organic extracts were washed with water $(3 \times 25 \mathrm{~mL})$ and brine $(3 \times 25 \mathrm{~mL})$, then dried over anhydrous magnesium sulfate. Evaporation of the solvent and crystallization of the resulting solid from a mixture of dichloromethane and methanol afforded 6 as a colorless solid $(6.2 \mathrm{~g}, 83 \%)$ : $\mathrm{mp}$ 88-89 ${ }^{\circ} \mathrm{C}\left(\mathrm{CH}_{2} \mathrm{Cl}_{2} / \mathrm{CH}_{3} \mathrm{OH}\right) ;{ }^{1} \mathrm{H}$ NMR $\left(\mathrm{CDCl}_{3}\right) \delta 5.91$ and 5.66 (sym m's, $\left.1 \mathrm{H}\right), 0.59-2.48(\mathrm{~m}$, $44 \mathrm{H}$, cholestane framework protons); ${ }^{13} \mathrm{C} N M R\left(\mathrm{CDCl}_{3}\right) \delta 12.0,12.1,12.3,18.8$ (s), 18.9, 21.2, 21.5 (s), 22.7, 23.0, 24.0, 24.3 (s), 24.4, 27.4 (s), 28.2, 28.42, 28.45 (s), 31.7, 32.0 (s), 33.6 (s), 34.2, 34.9 (s), 35.65 (s), 35.68, 36.0, 36.3, 36.5 (s), 39.7, 40.08, 40.10, 40.16 (s), 42.2, 42.67 (s), 42.68, 42.9 (s), 43.8, 48.8 (s), 52.9 (s), 53.7, 56.4, 56.53, 56.57 (s), 120.6, 121.2 (s), $127.7,133.2$ (s). Note that "(s)"' refers to the signals arising from $\sim 20 \%$ of the isomeric 6 . Anal. Calcd for $\mathrm{C}_{27} \mathrm{H}_{45} \mathrm{Br}$ : C, 72.14; $\mathrm{H}, 10.09$. Found: $\mathrm{C}, 72.13 ; \mathrm{H}, 10.10$. HRMS (m/z) calcd for $\mathrm{C}_{27} \mathrm{H}_{45} \mathrm{Br} 448.2700$, found 448.2705 .

Cholestanofluorene (4). A freshly prepared solution of 2-biphenylmagnesium bromide [from 2-bromobiphenyl (2.3 mL, $13.4 \mathrm{mmol})$ and excess magnesium turnings $(1.3 \mathrm{~g}, 53.4 \mathrm{mmol})$ in anhydrous tetrahydrofuran $(80 \mathrm{~mL})$ ] was transferred to a Schlenk flask containing $6(4.0 \mathrm{~g}, 8.9$ $\mathrm{mmol}$ ) and a catalytic amount of bis(triphenylphosphine)palladium dichloride $(0.25 \mathrm{~g})$ with the aid of a canula under an argon atmosphere and at $22^{\circ} \mathrm{C}$. The resulting yellow mixture was refluxed for $24 \mathrm{~h}$, cooled to room temperature, and quenched with saturated ammonium chloride solution $(50 \mathrm{~mL})$. The aqueous layer was extracted with dichloromethane $(3 \times 50 \mathrm{~mL})$ and the combined organic extracts were dried over anhydrous magnesium sulfate and filtered. Evaporation of the solvent in vacuo afforded crude $\mathbf{5}$ as a yellow solid that was used in the next step without purification. ${ }^{1} \mathrm{H}$ NMR $\left(400 \mathrm{MHz}, \mathrm{CDCl}_{3}\right) \delta 2.02-0.61(\mathrm{~m}, 44 \mathrm{H}$, cholestane framework protons), 5.53 and 5.30 (sym $\mathrm{m}, 1 \mathrm{H}$ ) due to a single olefinic proton from two isomers, $7.61-6.99(\mathrm{~m}, 9 \mathrm{H})$. 
To a solution of the isomeric mixture of biphenylcholestenes $\mathbf{5}$, from above, in anhydrous dichloromethane $(50 \mathrm{~mL})$ was added dropwise methanesulfonic acid $(2 \mathrm{~mL})$ under an argon atmosphere and at $0{ }^{\circ} \mathrm{C}$. The ice bath was removed and the resulting yellow solution was stirred for $1 \mathrm{~h}$ at $22^{\circ} \mathrm{C}$. The reaction mixture was quenched with aqueous sodium carbonate solution $(50 \mathrm{~mL})$ and the organic layer was separated. The aqueous layer was extracted with dichloromethane $(3 \times 50 \mathrm{~mL})$ and the combined organic extracts were dried over anhydrous magnesium sulfate and filtered through a short celite pad. Evaporation of the solvent and crystallization of the resulting solid from a mixture of dichloromethane/acetonitrile afforded $\mathbf{4}$ as a white crystalline solid $(2.7 \mathrm{~g}, 60 \%): \mathrm{mp} 181-182{ }^{\circ} \mathrm{C}\left(\mathrm{CH}_{2} \mathrm{Cl}_{2} / \mathrm{CH}_{3} \mathrm{CN}\right) ;{ }^{1} \mathrm{H} \mathrm{NMR}\left(\mathrm{CDCl}_{3}\right) \delta$ 0.72-2.32 (m, 46H, cholestane framework protons), 7.28-7.47 (m, 5H), 7.69-7.72 (m, 1H), $7.76(\mathrm{~d}, \mathrm{~J}=7,1 \mathrm{H}), 7.90(\mathrm{~d}, \mathrm{~J}=7,1 \mathrm{H}) ;{ }^{13} \mathrm{C} \mathrm{NMR}\left(\mathrm{CDCl}_{3}\right) \delta$ 12.1, 12.3, 18.9, 21.3, 22.8, 23.1, 24.1, 24.4, 28.2, 28.5, 29.0, 31.2, 32.2, 35.5, 35.8, 35.9, 36.0, 36.4, 38.5, 39.7, 40.3, 42.6, 42.8, 50.92, 55.1, 56.5, 56.8, 119.7, 120.2, 123.0, 125.6, 126.6, 127.04, 127.08, 127.5, 139.3, 140.1, 153.3, 154.3. Anal. Calcd for $\mathrm{C}_{39} \mathrm{H}_{54}$ : C, 89.59; H, 10.41. Found: C, 89.49; H, 10.52. HRMS $(\mathrm{m} / \mathrm{z})$ calcd for $\mathrm{C}_{39} \mathrm{H}_{54} 522.4231$, found 522.4226.

2,7-Dimethoxycholestanofluorene (9). Following a similar procedure, as above, a reaction of

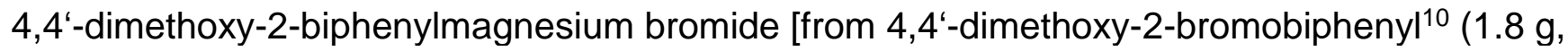
$6.2 \mathrm{mmol})$ in anhydrous tetrahydrofuran $(45 \mathrm{~mL})]$ with $6(1.84 \mathrm{~g}, 4.1 \mathrm{mmol})$ in the presence of a catalytic amount of bis(tri-phenylphosphine)palladium dichloride $(0.12 \mathrm{~g})$ followed by a reaction with methanesulfonic acid $(1 \mathrm{~mL})$ in dichloromethane $(50 \mathrm{~mL})$ afforded 9 , which was purified by column chromatography with use of hexanes-ethyl acetate as eluent. Recrystallization from a mixture of dichloromethane and acetonitrile afforded 9 as a white solid $(1.8 \mathrm{~g}, 77 \%): \mathrm{mp}$ 212-213 ${ }^{\circ} \mathrm{C}\left(\mathrm{CH}_{2} \mathrm{Cl}_{2} / \mathrm{CH}_{3} \mathrm{CN}\right) ;{ }^{1} \mathrm{H} \mathrm{NMR}\left(\mathrm{CDCl}_{3}\right) \delta$ 0.70-2.22 (m, 46H, cholestane framework protons), $3.87(\mathrm{~s}, 3 \mathrm{H}), 3.88(\mathrm{~s}, 3 \mathrm{H}), 6.82-6.94(\mathrm{~m}, 3 \mathrm{H}), 7.42-7.57(\mathrm{~m}, 3 \mathrm{H}) ;{ }^{13} \mathrm{C} \mathrm{NMR}\left(\mathrm{CDCl}_{3}\right) \delta$ 12.0, 12.3, 18.9, 21.2, 22.8, 23.0, 24.1, 24.4, 28.2, 28.5, 28.9, 31.4, 32.1, 35.3, 35.81, 35.85, 36.0, 36.4, 38.7, 39.7, 40.2, 42.3, 42.8, 50.7, 54.9, 55.7, 56.5, 56.7, 109.2, 110.7, 112.3, 113.5, 119.64, 119.67, 132.2, 133.1, 154.6, 155.7, 158.0, 159.2. Anal. Calcd for $\mathrm{C}_{41} \mathrm{H}_{58} \mathrm{O}_{2}: \mathrm{C}$, 84.48; $\mathrm{H}, 10.03$. Found: $\mathrm{C}, 84.08 ; \mathrm{H}, 10.02$. HRMS $(\mathrm{m} / \mathrm{z})$ calcd for $\mathrm{C}_{41} \mathrm{H}_{58} \mathrm{O}_{2} 582.4438$, found 582.4437 .

2,7-Di-tert-butylcholestanofluorene (10). Parent cholestano-fluorene 4 (0.52 g, 1.0 mmol) was readily transformed to 2,7-di-tert-butylcholestanofluorene (10) from a reaction of 4 with tert-butyl chloride $(0.32 \mathrm{~mL}, 3 \mathrm{mmol})$ in anhydrous dichloromethane $(25 \mathrm{~mL})$ in the presence of a catalytic amount of ferric chloride $(25 \mathrm{mg})$ with use of a standard literature procedure. ${ }^{13}$ Recrystallization of the resulting crude solid from a mixture of dichloromethane 
and acetonitrile afforded 10 as a white solid (0.58 g, 92\%): $\mathrm{mp} 168-169{ }^{\circ} \mathrm{C} ;{ }^{1} \mathrm{H}$ NMR $\left(\mathrm{CDCl}_{3}\right)$ $\delta$ 0.72-2.36 (m, 64H, cholestane framework and tert-butyl protons), 7.32-7.40 (m, 3H), 7.56-7.63 (m, 2H), $7.90(\mathrm{~s}, 1 \mathrm{H}) ;{ }^{13} \mathrm{C}$ NMR $\left(\mathrm{CDCl}_{3}\right) \delta$ 12.3, 12.4, 18.9, 21.4, 22.8, 23.1, 24.0, $24.4,28.2,28.5,29.0,31.4,31.9,32.6,35.0,35.1,35.8,35.9,36.01,36.04,36.4,38.8,39.8$, 40.3, 42.8, 42.9, 50.9, 55.9, 56.4, 56.9, 118.9, 119.2, 119.5, 122.6, 123.9, 124.1, 136.8, 137.4, 148.9, 150.2, 153.2, 154.1. Anal. Calcd for $\mathrm{C}_{47} \mathrm{H}_{70}$ : C, 88.89; H, 11.11. Found: $\mathrm{C}, 88.57 ; \mathrm{H}$, 10.97. HRMS $(\mathrm{m} / \mathrm{z})$ calcd for $\mathrm{C}_{47} \mathrm{H}_{70} 634.5472$, found 634.5478 .

2,7-Dibromocholestanofluorene (11). Parent cholestanofluorene 4 (0.52 g, $1.0 \mathrm{mmol})$ was readily transformed to 2,7-dibromo-cholestanofluorene (11) from a reaction

of 4 with bromine $(0.48 \mathrm{~g}, 3 \mathrm{mmol})$ in dichloromethane $(25 \mathrm{~mL})$ at $22^{\circ} \mathrm{C}$ with use of standard procedures. Yield: $0.66 \mathrm{~g}, 97 \%$; mp $198-199{ }^{\circ} \mathrm{C}$; ${ }^{1} \mathrm{H} \mathrm{NMR}\left(\mathrm{CDCl}_{3}\right) \delta 0.71-2.23(\mathrm{~m}, 46 \mathrm{H}$, cholestane framework protons), 7.42-7.58 (m, 5H), $7.95(\mathrm{~d}, 1 \mathrm{H}) ;{ }^{13} \mathrm{C} \mathrm{NMR}\left(\mathrm{CDCl}_{3}\right) \delta 12.0$, 12.3, 18.9, 21.2, 22.8, 23.0, 24.0, 24.3, 28.2, 28.4, 28.8, 30.9, 32.0, 35.3, 35.8, 36.0, 36.4, $38.1,39.7,40.1,42.6,42.8,51.3,54.8,56.5,56.6,120.9,121.1,121.5,121.7,126.5,128.7$, 130.4, 137.2, 138.0, 154.8, 156.1. Anal. Calcd for $\mathrm{C}_{39} \mathrm{H}_{52} \mathrm{Br}_{2}$ : $\mathrm{C}, 68.82 ; \mathrm{H}, 7.70$. Found: $\mathrm{C}$, 68.53; $\mathrm{H}, 7.61$. HRMS $(\mathrm{m} / \mathrm{z})$ calcd for $\mathrm{C}_{39} \mathrm{H}_{52} \mathrm{Br}_{2} 678.2438$, found 678.2436.

\section{Acknowledgment}

We thank the Petroleum Research Fund, administered by the American Chemical Society, and the National Science Foundation (Career Award) for financial support.

\section{References}

(1) (a) Kraft, A.; Grimsdale, A. C.; Holmes, A. B. Angew. Chem., Int. Ed. 1998, 37, 402.

(b) Mitschke, U.; Bäuerle, P. J. Mater. Chem. 2002, 10, 1471. (c) Rees, I. D.; Robinson, K. L.; Holmes, A. B.; Towns, C. R.; O'Dell, R. MRS Bull. 2002, 27, 451. (d) Barbec, J.; Sariciftci, N. S.; Hummelen, J. C. Adv. Funct. Mater. 2001, 14, 15.

(2) (a) Watson, M. D.; Fechtenkötter, A.; Müllen, K. Chem. Rev. 2001, 101, 1267. (b) Sonar, P.; Zhang, J.; Grimsdale, A. C.; Müllen, K.; Surin, M.; Lazzaroni, R.; Leclère, P.; Tierney, S.; Heeney, M.; McCulloch, I. Macromolecules 2004, 37, 709.

(3) For other usage of cholestane framework, see: (a) Yus, M.; Soler, T.; Foubelo, F. Tetrahedron: Asymmetry2001, 12, 801. (b) Dogariu, A.; Gupta, R.; Heeger, A. J.; Wang, H. Synth. Met. 1999, 100, 95. (c) Marcelis, A. T. M.; Koudijs, A.; Sudhoelter, E. J. R. Liq. Cryst. 1995, 18, 843. (d) Erker, G.; Mollenkopf, C. J. Organomet. Chem. 1994, 483, 173. (e) Breslow, R.; Wiedenfeld, D. Tetrahedron Lett. 1993, 34 , 1107.

(4) (a) Carreno, M. C.; Garcia, I.; Ribagorda, M.; Merino, E.; Pieraccini, S.; Spada, G. P. Org. Lett. 2005, 7, 2869. (b) Feringa, B. L.; van Delden, R. A.; Koumura, N.; Geertsema, E. M. Chem. Rev. 2000, 100, 1789. (c) Mori, T.; Inoue, Y. J. Phys. Chem. A2005, 109, 2728. 
(5) (a) Marcelis, A. T. M.; Koudijs, A.; Sudhoelter, E. J. R. Liq. Cryst. 1995, 18, 843. (b) Aldred, M. P.; Eastwood, A. J.; Kitney, S. P.; Richards, G. J.; Vlachos, P.; Kelly, S. M.; O'Neill, M. Liq. Cryst. 2005, 32, 1251 and references cited therein.

(6) Kumada, K. Pure Appl. Chem. 1980, 52, 669. Also see: (a) Rathore, R.; Abdelwhaed, S. H.; Guezi, I. A. J. Am. Chem. Soc. 2003, 125, 8712. (b) Rathore, R.; Deselnicu, M. I.; Burns, C. L. J. Am. Chem. Soc. 2002,124, 14832.

(7) Compare: Napolitano, E.; Fiaschi, R.; Mastrorilli, E. Synthesis 1986, 122.

(8) Li, T.-S.; Li, L.-J.; Yang, F. J. Chem. Soc., Perkin Trans. 1 1998, 3561.

(9) (a) Note that the two benzenoid rings of the fluorene moiety in 4 show different ${ }^{1} \mathrm{H} /{ }^{13} \mathrm{C}$ signals due to the rigidity of cyclohexane framework, which does not allow chair-to-chair interconversions on the NMR time scale. It is expected that the simple spiro[cyclohexane-1,9'-fluorene] will show the presence of the symmetrical fluorene moiety by ${ }^{1} \mathrm{H} /{ }^{13} \mathrm{C}$ NMR spectroscopy because it can undergo rapid chair-to-chair interconversions on the NMR time scale, e.g., see: Ohwada, T. J. Am. Chem. Soc. 1992, 114, 8818. (b) Cambridge Crystallographic Database, 2006.

(10) Sparling, J.; Fung, D.; Safe, S. Biomed. Mass Spectrom. 1980, 7, 13.

(11) Rathore, R.; Burns, C. L.; Deselnicu, M. I. Org. Synth. 2005, 82, 1.

(12) Rathore, R.; Kumar, A. S.; Lindeman, S. V.; Kochi, J. K. J. Org. Chem. 1998, 63, 5847 and references cited therein.

(13) Rathore, R.; Burns, C. L. J. Org. Chem. 2003, 68, 4071.

(14) Setayesh, S.; Marsitzky, D.; Muellen, K. Macromolecules 2000, 33, 2016 and references cited therein.

(15) Rault-Berthelot, J.; Simonet, J. J. Electroanal. Chem. 1985, 182, 187.

(16) Bruce, W. F. Organic Syntheses; Wiley: New York; Collect. Vol. 2, p 139; Vol. 17, p 43. 